\title{
THE WHY AND HOW VR IN SCHOOLS: A PREFERRED FUTURE PEDAGOGIC MISSION BY A GROUP OF WORLDWIDE EXPERTS IN VR AND EDUCATION
}

\author{
David Passig and Aviva Sharbat \\ Bar-Ilan University, Israel
}

\begin{abstract}
The exploration of virtual reality as a potential alternative space for human activity presents great challenges for contemporary thinking. This paper attempts to report a recent scholarly discussion about virtual reality and its implications for future K-12 education. This study did not aim to predict the future of VR in education. It aimed to evaluate the preferred mission of VR before the technology is widely used in schools. This study, in a sense, is taking a proactive approach in evaluating the needs and the appropriate educational theories to guide the development of VR before its widespread utilization. Other studies have aimed at observing evidence that show trends. However, this study with 50 worldwide VR experts assisted in drafting a preferred VR future pedagogic mission.
\end{abstract}

\section{Introduction}

The purpose of this research was to lead a debate and reach an agreement among a group of experts concerning the future of VR in schools, which is both preferable and possible. We offered a group of experts who are involved with VR and education an opportunity to take part in an online, future oriented discussion with iterative feedback through e-mail, concerning the rationale of using VR in schools in the future. This research was conducted with 50 worldwide experts from the U.S, Canada, UK, Germany, Switzerland, Austria, Greece, Australia, New Zealand, Singapore, and Venezuela.

In this research we used a version of the classical Delphi forecasting methodology, called the ImenDelphi (ID) technique (Passig 1997, 1998, 2000). The ID procedure, as opposed to the Delphi technique, does not direct the participants to foresee future events. Instead, the procedure guides them towards general agreement and future growth. They are directed to reach one of the following five types of agreement: total agreement, majority agreement, bipolarity agreement, partial agreement, and total disagreement. The agreement indicates the responsibility, self-awareness, and concept enhancement of the participants.

The results of this study indicate that the perceptions and images of the future (Kurth-Schai 1984) held by the participants point to a striking transformation of the perceived role they would like to designate to future developers of VR materials for use in the curricula.

\section{VR in education}

VR is a three-dimensional, participatory, multi-sensory, computer-based simulated environment occurring in real time. Applied to instruction, it has the potential to revolutionize teaching and learning processes (Randall 1992). It has been defined as a highly interactive, computer-based, sensory experience by using computer graphics, sounds, and images to reproduce electronic versions of real-life situations. 
For many researchers, VR has the potential to be a powerful new tool in the classroom. It can extend the classroom via new windows into other realities. By reflecting the real world, the simulation gives a participant the chance to try out different options without the dangers, expense, or time consumption that doing the 'real thing' might involve. One may also try out scenarios that are actually impossible to do in real world and determine which scenarios present the best chance of accomplishment (Pantelidis 1993).

In recent years the community of scholars working on VR in education has been vigorously evaluating technological, social, and cognitive trends that are shaping the evolving VR materials for use in schools. Many of the studies published in the last decade point to drastic changes in the hardware and software of VR infrastructures that can be used for teaching purposes (Bricken 1991, Winn 1995, Salis \& Pantelidis 1997, Youngblut 1998). Therefore, VR technology has been widely proposed as a major technological advance that can offer significant support for education.

In this study, however, a group of experts was provided with the opportunity to discuss their preferred direction that VR should take in the curriculum before its worldwide dissipation.

\section{Methodology}

The Imen-Delphi (ID) procedure was designed to develop shared future images among a group of people sharing a common future interest (Passig 1997, 1998, 2000). Its main objective is to enable the group to efficiently cope with complex problems regarding a shared future and to establish a collective future mission. The ID procedure is geared to promote the responsibility and the self-awareness of the participants towards their probable and preferable future.

The ID was developed as a variant of the Delphi (Linstone \& Turoff 1975) to enable a group of participants sharing a common future to learn the trends, interact, discuss their meaning, and generate desired solutions to forthcoming dilemmas. Thus this research is best described as an exploratory investigation into two aspects of the participants' future images: (1) the complexity of their views regarding VR in K-12 education, and (2) their capacity to draw upon their future images and agree on a list of future mission statements.

The ID procedure is based on three rounds with iterative feedback. In the first round the researchers provide the participants with a number of "teasers" and ask them to draft questions around the teasers. The researchers later draft the first questionnaire from the collection of questions that were received from the participants. The participants then receive the first-round questionnaire for completion (see a sample in Fig. 1).

The second round includes a list of statements that are drafted from the answers collected from the first questionnaire. On this round the participants are asked to organize their preferences, their desires, and their vision regarding each of the statements on the list (see a sample in Table 2).

In the third round the participants receive a final list of agreed upon mission statements. This list is given to the participants to express their satisfaction with the present situation. They are also requested to draft recommendations for future implementation (see a sample in Table 3).

The exploration of virtual reality as a potential alternative space for human activity presents great challenges for contemporary thinking. This paper attempts to report a recent scholarly discussion about virtual reality and its implications for future K-12 education. This study did not aim to predict the future of VR in education. It aimed to evaluate the preferred mission of VR before the technology is widely used 
in schools. In a sense, this study is taking a proactive approach in evaluating the needs and the appropriate educational theories to guide the development of VR before its widespread utilization. Other studies have aimed at observing evidence that show trends. However, this study used 50 worldwide VR experts to assist in drafting a preferred VR future pedagogic mission.

\section{Procedure}

In this study 50 participants (see table 1) from worldwide agencies, organizations, and academic institutes were provided with an opportunity to take part in a future oriented discussion about VR in education. This group of experts formed an ad-hoc virtual panel of people from around the globe. Most of the participants hold key positions at universities, research institutes, and the industry of educational VR. The scholars among them have conducted studies and published scientific papers and books. The participants were aware of the names of their colleagues in this panel, but the whole procedure was carried out anonymously.

We collected a list of 116 experts who are working on different aspects of VR and education through various channels - from VR electronic news groups to lists of participants in VR conferences. We addressed them with the rationale of the study and asked for their consent to participate in the panel. Fifty-three sent their consent to participate, 22 refused to participate, and the rest did not answer. 50 worldwide experts ended up taking part in this electronic conference - 15 women and 35 men.

\begin{tabular}{|l|l|l|l|}
\hline $\begin{array}{l}\text { Expertise } \\
\text { Country }\end{array}$ & $\begin{array}{l}\text { Distinguished } \\
\text { scholars }\end{array}$ & $\begin{array}{l}\text { Industry } \\
\text { developers }\end{array}$ & $\begin{array}{l}\text { M.A \& Ph.D. students working } \\
\text { on educational VR }\end{array}$ \\
\hline United States & 17 & 6 & 4 \\
\hline Canada & 1 & - & - \\
\hline United Kingdom & 3 & 1 & 5 \\
\hline Germany & - & - & 1 \\
\hline Switzerland & 1 & - & - \\
\hline Austria & 1 & - & - \\
\hline Greece & 1 & 1 & 2 \\
\hline Australia & 2 & - & - \\
\hline New Zealand & 1 & - & 1 \\
\hline Singapore & - & - & 1 \\
\hline Venezuela & 1 & - & - \\
\hline Total=50 & 28 & 8 & 14 \\
\hline & & &
\end{tabular}

Table 1: Participants

The participants were asked to collect studies (teasers) regarding trends in two aspects of future educational VR: the way and the reason to integrate VR in schools, and the why and how to make use of VR technologies in future curriculum (K-12). We asked them to provide us with teasers, and we engaged also in collecting others (see sample on fig.1). By intellectual-teaser we meant any kind of references, short summaries, or excerpts (10 sentences) from original articles, studies, visionary notes, or any other published information concerning the future of VR in education that correspond to the two aspects in debate - the why and how. It was necessary to provide the participants with a number of thoughtprovoking intellectual teasers to assist them in generating thoughtful questions to be addressed later to the whole panel. 


\section{ID Iterative Rounds}

We then produced a file summarizing in it the variety of teasers submitted by the participants as well as the researchers (20 teasers on total). We left space at the bottom of each teaser and asked the participants to draft questions for later presentation to the whole panel. The file was attached to an email sent to the 50 participants. The participants were asked to do the following:

- Read the attached excerpts.

- Imagine the other participants sitting in front of them reading the same material.

- Imagine they had the opportunity to ask them questions on how they view the future of educational VR in light of the teasers they all had just read.

- Think about questions that would extract images from the participants' minds and hearts concerning the future.

- Challenge the participants' motivations and self-expectations.

- Draft actual questions relevant to the participants' scope of communal issues.

\section{First Round}

In a very real sense the causes of the present lie in the future, which means that the image of the future people have in their minds can have a dramatic effect on what they do right now. We have stressed that it is important to collectively learn and create complex images of the future, since on that basis it is possible to develop skills through which one may adapt to change and create change.

We then developed a second file in which we organized the questions (28 out of 413, clarifying and combining the most relevant ones) around the two categories of future VR in education. (For a sample of the first round questionnaire, see fig. 1).

The participants were asked to do the following:

- To read the attached excerpts and projections.

- To answer the questions briefly.

- To enlarge upon their perspectives, notions and objectives in dealing with the issues.

- To submit questions to the rest of the panel if they choose to do so.

\section{The Why • SELF-DIRECTED LEARNING・Theory}

The use of VR in education may encourage self-directed learning in the student. Bruner (1968), Vygotsky (1978), and Piaget have emphasized the importance of self-directed activity in their theories

Brown, D. J, Mikropoulos, T. A, \& Kerr, S.J. (1996) A Virtual Laser Physics Laboratory. VR in the Schools December 1996, Vol. 2: 3

Sample of questions to participants:

8. How would you define VR in education?

9. What should be the leading education theory in the development of VR educational material (if any)?

Figure 1: Sample of the First-Round Questionnaire 


\section{Second Round}

The purpose of the second round was to facilitate a thorough online interaction to generate specific ideas listed as statements. Therefore the second round questionnaires were designed around proposed mission statements. The statements that comprised the second round were narrated by the researchers who organized the answers received from the first round into two reports coinciding with the original two categories in debate, the why and how VR in K-12. These reports were e-mailed to the participants. The second round questionnaire was comprised of 72 suggested future mission statements (for a sample, see table 2).

The purpose of this round was to help organize thoughts and focus the discussion around more specific solutions for 1) preferred futures, 2) expected futures, and 3) potential (or prospective) futures. The Imen-Delphi procedure is aimed at producing some type of agreement on an alternative future mission: complete disagreement, plurality, bipolarity, majority, or complete consensus. The second round was designed to achieve that purpose.

\begin{tabular}{|l|l|l|l|}
\hline Statements & $\begin{array}{l}\text { Question I } \\
\text { Do you prefer this } \\
\text { statement to be fulfilled } \\
\text { in the future? }\end{array}$ & $\begin{array}{l}\text { Question II } \\
\text { What is the likelihood that } \\
\text { this statement will be } \\
\text { applied in the future? }\end{array}$ & $\begin{array}{l}\text { Question III } \\
\text { Is this statement } \\
\text { feasible to be realized } \\
\text { in the future? }\end{array}$ \\
& $\begin{array}{l}\text { B. Possibly yes } \\
\text { C. Probably no } \\
\text { D. Absolutely no }\end{array}$ & $\begin{array}{l}\text { B. Certain } \\
\text { C. Protain } \\
\text { D. Improble }\end{array}$ & $\begin{array}{l}\text { B. Uncertain } \\
\text { C. Probable } \\
\text { D. Improbable }\end{array}$ \\
\hline $\begin{array}{l}\text { 8. Ed. VR will provide } \\
\text { learning experience } \\
\text { different from other } \\
\text { media }\end{array}$ & & & \\
\hline $\begin{array}{l}\text { 9. We will be able to } \\
\text { evaluate Ed. VR } \\
\text { learning experience } \\
\text { using some of the same } \\
\text { parameters as the ones } \\
\text { used to measure the old } \\
\text { experiences. }\end{array}$ & & & \\
\hline
\end{tabular}

Table 2: Sample of the Second-Round Questionnaire

\section{Third Round}

The list of mission statements that comprised the third round was adapted from the mission statements of the second round that received the majority vote as being definitely preferred achievements in the future (Question I). The purpose of the third round was to have the panelists take responsibility, formulate a final proposed list of future mission statements, and generate new ideas and recommendations. Table 3 is a sample of the third round questionnaire. 


\begin{tabular}{|c|c|c|c|c|}
\hline \multicolumn{2}{|c|}{ Agreed upon Future Mission-Statements } & $\begin{array}{l}\text { Participants' votes on } \\
\text { their preference of } \\
\text { this statement to the } \\
\text { future? } \\
\text { A. Definitely yes } \\
\text { B. Possibly yes } \\
\text { C. Probably not } \\
\text { D. Absolutely not } \\
\text { (from 2nd round) }\end{array}$ & $\begin{array}{l}\text { Please mark } \\
\text { whether or not } \\
\text { you are } \\
\text { satisfied with } \\
\text { the way Ed. } \\
\text { nowadays } \\
\text { uses the } \\
\text { potential of } \\
\text { VR expressed } \\
\text { in each of } \\
\text { these } \\
\text { statements } \\
\text { y/n }\end{array}$ & $\begin{array}{l}\text { Please, give } \\
\text { any } \\
\text { suggestions as } \\
\text { to how we can } \\
\text { promote the } \\
\text { implementatio } \\
\text { n of these } \\
\text { statements in } \\
\text { future VR and } \\
\text { Ed. }\end{array}$ \\
\hline 2. & $\begin{array}{l}\text { VR in ed. will have to provide the } \\
\text { students with an opportunity to } \\
\text { experience sensory interactive learning } \\
\text { environments that will enable them to } \\
\text { move from passive learning to active } \\
\text { learning. }\end{array}$ & $\begin{array}{l}\text { A. } 82 \% \\
\text { B. } 18 \% \\
\text { C. } 0 \% \\
\text { D. } 0 \%\end{array}$ & & \\
\hline 10. & $\begin{array}{l}\text { Educational VR will have to provide } \\
\text { "new intelligences". }\end{array}$ & $\begin{array}{l}\text { A. } 45 \% \\
\text { B. } 41 \% \\
\text { C. } 5 \% \\
\text { D. } 5 \%\end{array}$ & & \\
\hline
\end{tabular}

Table 3: Sample of the Third-Round Questionnaire

\section{Future Mission Statements}

The final list of the preferred future mission-statements was adapted from the mission statements of the third round that received the majority vote as being the most preferred goals for the future of VR in education (Question I). The third round questionnaire comprised a final list of 46 agreed upon future mission statements. The following is the complete list that the majority of the participants accepted to represent the preferred future mission of VR in education. The final list is divided into subcategories for ease of reading.

\subsection{EDUCATIONAL VR CHARACTERISTICS}

- VR in education has to be defined as a computer-generated space that provides sensory immersion using 3-D interactive multi-user worlds and application of virtual environments for learning.

- VR in education will have to provide students with an opportunity to experience sensory interactive learning environments, enabling them to move from passive learning to active learning.

- Novelty, interactivity, simulation, exciting scenarios, feeling of exploration and discovery, and making learning active will have to make Educational VR interesting and motivating enough for students to want to use it.

- Immersive quality, free navigation, creative input, and connection to the technology of computer games will have to make Educational VR interesting and motivating enough for students to want to use it. 


\subsection{ATTRACTIVE VIRTUAL ENVIRONMENTS}

- Educational VR will have to change the physical structure of the classroom. The classroom will require no walls or boundaries.

- Educational VR will have to be an augmentation to traditional learning paradigms.

- Educational VR will have to teach people with psychological phobias how to cope with them.

- Educational VR will have to be able to support cooperative learning among students at different locations by allowing them to share experiences and explore a common environment.

- Educational VR will have to provide equal support for students needing more structure, having learning disabilities, etc. by making all assumptions explicit and creating a flexible design of environments.

\section{NEW COGNITIVE ASPECTS}

- Educational VR will have to provide "new intelligences".

- Learning in Educational VR will have to be cognitively different than that of a traditional educational environment by allowing the students to use simulated environment actively and interactively. It will have to combine abstract learning with understanding coming from experience to help in developing imagination.

- Learning in Educational VR will have to be cognitively different than that of a traditional educational environment by providing multi-sensory interface.

- Learning in Educational VR will have to be cognitively different from that of a traditional educational environment by allowing direct feedback, creativity, and alternate learning styles.

- Educational VR will have great potential in the application of spatial thinking.

- Educational VR will have great potential in the application involving topics where students are unable to build mental models and representations.

\subsection{VR SUBJECT MATTERS}

- Subject matters in the humanities such as languages, social studies, and history will have to be served by Educational VR.

- Subject matter in the sciences such as mathematics, chemistry, and physics will have to be served by educational VR.

- The applications where Educational VR has great potential will have to be all the areas in which visualization, simulation, or "learning by doing" activities are essential.

\subsection{ACHIEVEMENTS' EVALUATION}

- The assessment of Educational VR achievements will have to be conducted with a range of methodologies from various disciplines.

- We will have to be able to evaluate Educational VR learning experience using some of the same parameters as the ones used to measure the old experiences.

- We will have to educate teachers and others in the appropriate use of VR to ensure that Educational VR will be applied in the most appropriate areas and to prevent its misuse. 


\subsection{LEADING PEDAGOGICAL THEORIES}

- Constructivism will have to be the leading educational theory in the development of Educational VR materials.

- VR learning tools will have to assure results that are more positive for our students by using the same philosophy of experimentalism and criticism as a neo-Deweyan paradigm.

- Vygotsky's social theories of education will have to be the leading theory in the development of Educational VR materials.

- Any theory that allows open learning environment can be suitable in the development of Educational VR materials.

- Educational VR technology will have to be developed to its full potential by rewriting the curriculum in terms of interactive problem solving.

\subsection{QUALITY STANDARDS AND METHODS}

- Quality standards will have to be imposed by the marketplace, government, and international regulatory bodies for Educational VR materials.

- Educational VR associations will have to advise governments about any necessary regulations to ensure that VR is only applied in the most appropriate areas and to prevent its misuse.

- The same standards as those imposed on ordinary curriculum will have to be imposed on Educational VR materials.

- We will have to be able to ensure that Educational VR is applied in the most appropriate areas and prevent its misuse by encouraging the publication and discussion of criticisms and alerts about the dangers inherent to the new media, as well as addressing moral and ethical issues.

- VR learning tools will have to assure results that are more positive for our students by communicating and making results available through the Internet for public scrutiny.

- The methods that will have to be used in the design of Educational VR applications will be trial and error, customer feedback, and monitoring of effects on health.

- VR learning tools will have to assure results that are more positive for our students by doing initial pilot studies and control studies to examine learning effectiveness.

- VR learning tools will have to assure results that are more positive for our students by developing appropriate methods for observation and evaluation of students' behavior and response to the new media.

\subsection{INFRASTRUCTURE ANS HUMAN RESOURCES}

- The infrastructure needed to support the use of Educational VR should be just regular computers and trained human resources for facilitating and assisting students.

- Educational VR technology will have to be developed to its full potential by encouraging or sponsoring collaboration between the workplace \& education.

- The human infrastructure needed to support the use of Educational VR should be teams from all walks of life, e.g. from universities, K-12 schools, business, government, religious institutes, parents, and other community agencies.

- We will have to train teachers to use this technology by using the methods of "multiplying effect" (teachers training other teachers). 


\subsection{FUTURE VR RESEARCH BASE}

- The basic research that will have to assist instructional designers in developing effective VR learning environments is research into the effects of various aspects of VR on learning different subjects.

- The necessary research that will have to assist instructional designers in developing effective Educational VR learning environments is research into the health effects of VR.

- The necessary research that will have to assist instructional designers in developing effective Educational VR learning environments is research into the application of VR for spatial problems.

- The necessary research that will have to assist instructional designers in developing effective Educational VR learning environments is research on motivation and exploration.

- The necessary research that will have to assist instructional designers in developing effective Educational VR learning environments is research into Educational VR standards.

- The necessary research that will have to assist instructional designers in developing effective Educational VR learning environments is research on how one learns, using different methods and techniques, at every age, and every type of situation.

- Multimedia is a field from which Educational VR research will have to learn a lot.

- The research that will have to be necessary to assist instructional designers in developing effective Educational VR learning environments is research involving the practitioners or the classroom teachers.

\section{Discussion}

The mutually agreed upon concepts and mission statements regarding the use of VR in schools point to a new pedagogy that needs to be addressed by developers, users, scholars, and teachers. The agreed upon future mission statements in this research aimed to define the role of VR technology and its contribution to education. The list points to certain fields and subjects where VR could be especially helpful. It demonstrates the standards and methods that can support the VR technology and can lead to its more effective utilization in learning. The results express the hope of this group of experts that VR will change the structure of the classroom, the curriculum, and the learning style of the students. Moreover, they hope that VR will enable students to cope with various learning disabilities.

Different methods of evaluating the achievement of users of VR were discussed in this exercise, based on the assumption that VR improves the cognitive ability and provides a new intelligence. The agreed upon future mission statements reveal that the development of VR technologies can and will lead to positive effects on the learning process and the learner. Therefore this group of experts emphasized the practical aspects of implementing the VR technology in schools and point out the necessity of future research that would lead to a more efficient use of that technology. 
It seems that this group of experts perceives the introduction of VR into schools in a positive light. They are convinced that this new technology is unique and has a great potential to restructure the classroom and the student's learning style, as well as to provide the student with new cognitive skills. The general aspiration is that VR will provide new learning aspects in addition to traditional ones.

According to this group of experts, the use of VR in education can be aimed to provide more attractive, motivating, and much more interesting learning experiences to future students. They would like to see the novelty, the immersion, the stimulation of the senses, and the feeling of exploration encouraging the student to move from passive learning to active learning. Most of all, they would like to see VR technology supporting the cooperative learning environment we all strive for.

The participants agreed that the fields where VR has the greatest potential are the ones involving visual simulation, spatial thinking, and learning by doing activities. By "spatial thinking" the participants refer to the spatial aspect of Gardner's Multiple Intelligence - the seven learning styles (Gardner 1983). By "new intelligence" the participants refer to "a new literacy" different from the one we have been accustomed to in expressing ourselves - the familiar systems of symbols: text, pictures, video, etc. Therefore expression in virtual environments creates a new human means of expression that restores the form of interpersonal communication to a more intuitive one (Passig 1996). In other words, the new media of VR environments may have unique cognitive representations, and new "intelligence" might be possible as a result of the exposure to these attributes.

Indeed, the participants in this study express much hope in the future of VR in education. They suggest encouraging the training of teachers with this technology, as well as encouraging teachers to use VR in the curriculum.

\section{Conclusion}

The results of this research indicate that the perceptions, and images of the future held by this specific group of panelists point to a striking transformation of the perceived role they would like to designate to future developers of VR materials for use in the curricula. They would like to see their role shifting from providers of supplementary teaching aides to primary providers of a variety of new and alternative classroom structures, learning styles, and cognitive skills. The mutually agreed upon concepts and mission statements regarding the use of VR in schools point to a new pedagogy that needs to be addressed by developers, users, scholars and teachers. 


\section{REFERENCES}

Bricken, M. S. (1991) Virtual reality learning environments: Potential and challenges. Computer Graphics Magazine, vol. 25, no. 3.

Gardner, H. (1983) Frames of mind: The theory of multiple intelligence. Basic books: New York, USA.

Kurth-Schai, R. (1984) Reflections from the Hearts and Minds of Children: A Delphi Study of Children's Personal, Global, and Spiritual Images of the Future. Ph.D. Dissertation, University of Minnesota, USA.

Linstone \& Turoff (1975). The Delphi Method: Techniques and Applications. London: Linstone \& Turoff (Eds) Addison-Wesley Publishing.

Pantelidis, V. S. (1993). Virtual Reality in the Classroom. Educational Technology. Vol. 33 (April \# 4) pp.23-27.

Passig, D. (1996). Virtual Literacy: Literacy in Virtual Learning Environments. In Howard, F. Didsbury, Jr. (ed.) Futurevision: Ideas, Insights, And Strategies. World Future Society, Washington (133146).

Passig, D. (1997). Imen-Delphi: A Delphi Variant Procedure for Emergence. Human Organization. The Society for Applied Anthropology, 56(1), 53-63.

Passig, D. (1998). An Applied Social Systems Procedure for Generating Purposive Sound Futures. Systems Research and Behavioral Science, The Official Journal of the International Federation for Systems Research. J. Wiley \& Sons. West Sussex, England. Winter 1998. Vol. 14:1 (67-78).

Passig, D. \& Sharbat, A. (2000) Electronic-Imen-Delphi (EID): An Online Conferencing Procedure. Educational Media International Journal. In print by March 2000.

Randall, J. P. (1992). The Emerging Potential of Virtual Reality in Postsecondary Education. New Directions for Teaching and Learning. No. 51 pp.77-81.

Salis, C. \& Pantelidis, V. S. (1997) Designing Virtual Environments for Instruction: Concepts and Considerations. VR in the Schools, Virtual Reality and Education Laboratory East Carolina University Greenville, North Carolina USA Volume 2, Number 4.

http://eastnet.educ.ecu.edu/vr/vrits/2-4salas.htm.

Winn, B. (1995) The Virtual Reality Roving Vehicle Project. Human Interface Technology Laboratory's Learning Center, University of Washington in Seattle. http://www.hitl.washington.edu

Youngblut, C. (1998) Educational Uses of Virtual Reality Technology. Paper presented at the VRET'98 Conference, Virtual Reality in Education \& Training 6-9 July 1998, London, UK. http://www.hitl.washington.edu/scivw/youngblut-edvr/vred.html 


\section{BIOGRAPHIES}

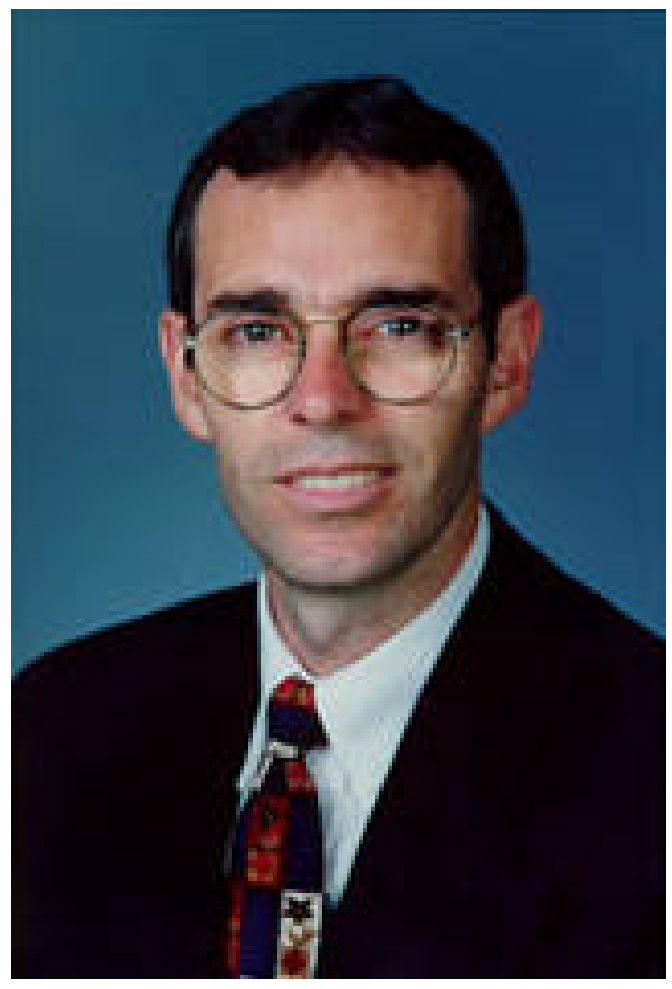

David Passig, $\mathrm{PhD}$, is teaching educational futures, systems theory, and is heading the Virtual Reality $\mathrm{Lab}$ at the School of Education, Bar-Ilan University, Israel. He holds a Ph.D. degree in Future Studies from University of Minnesota, Minneapolis, USA. He has consulted for many institutes and companies in Israel, Western Europe, and North America, including the Israeli Ministry of Education, the Israeli HMO, Dolev Insurance Company, Bank Hapoalim, and the Israeli Air Force.

\section{Contact information:}

Dr. David Passig

School of Education

Bar-Ilan University 52900 Ramat-Gan, Israel.

Tel: $+972-9-8340042$

Fax: $+972-3-5353319$

Cell: $+972-52-782377$

Email link: mailto:passig@mail.biu.ac.il

Web site: http://faculty.biu.ac.il./ passig

Mrs. Aviva Sharbat is a doctoral student in the College of Education, Graduate Department of Educational Technology, Bar-Ilan University, Ramat-Gan, Israel. Ms. Sharbat is working under the direction of Dr. David Passig. Ms. Sharbat may be reached at 10 Heleny Hamalka St. 46768 Herzlliya, Israel.

\section{Contact information:}

Aviva Sharbat

School of Education

Bar-Ilan University

52900 Ramat-Gan, Israel.

Telephone: $+972+9+9561851$

Fax: $+972+9+9514849$

Email link: mailto:sharbata@mail.inter.net.il 